\title{
A Percepção Ambiental pelos Alunos da UFMT- Campus Cuiabá como Instrumento de Planejamento de Sistemas de Gestão Ambiental nas Empresas.
}

\section{Environmental Perception as a Tool for Planning Environmental Management Systems in the Enterprise}

\author{
Mayara Cristina Santos Marques ${ }^{1}$, Margarida Marchetto ${ }^{2}$, José Roberto Temponi de Oliveira ${ }^{3}$, \\ Sheila C. Ferreira Leite ${ }^{4}$. \\ ${ }^{1}$ Graduada em Engenharia Sanitária e Ambiental ${ }^{1}$ Prof $^{a} \operatorname{Dr}^{a}$ da FAET - Dep.Eng. Sanitária e Ambiental - Universidade Federal de Mato \\ Grosso- UFM; m_marchetto@ufmt.br ${ }^{1}$ Prof. Dr. do ICET - Dep. Estatística - UFMT; ${ }^{4}$ Prof. Dr ${ }^{\mathrm{a}}$. - Dep. Economia - UFMT.
}

Trabalho recebido em 10/05/14 aceito: 10/07/14 publicado: Novembro de 2014

Resumo: Devido aos problemas ambientais que vem ocorrendo, as empresas passaram a sofrer uma forte pressão por parte dos governos e até mesmo pela sociedade para que invistam em mecanismos de produção menos impactantes ao meio ambiente. Nesse contexto, a certificação por meio da ISO 14001 surge como uma oportunidade para as empresas, além de cumprirem as exigências legais, conquistarem um mercado consumidor que cada vez mais se preocupa com as questões ambientais. Desse modo a fim de verificar a percepção ambiental e o conhecimento dos consumidores a respeito da preocupação ambiental das empresas, em especial os estudantes da Universidade Federal de Mato Grosso, e a possível influência na sua decisão de compra foi realizado uma pesquisa sob a forma de questionários. Foram obtidas 135 respostas em que foram observadas que a partir da percepção ambiental apresentada pelos estudantes de maneira geral, a maioria destes se mostrou preocupado com as questões ambientais e a favor de empresas fabricantes de produtos que em sua manufatura minimizem o impacto ao meio ambiente. Porém, de acordo com as respostas observa-se que ainda não é significante o conhecimento a respeito de sistemas de gestão ambiental adotados, em especial a ISO 14001.

Palavras-chave: ISO 14001, percepção ambiental, influência do mercado consumidor.

Abstract: Due to the environmental problems that is been occurring, the companies starts to be pressed from the government and even from the society to invest in less harmful production mechanisms to the environment. In that context, the certification from the ISO 14001 appears as an opportunity of the companies to gain a consumer market which is more and more concerned about the environmental issues, in addition to accomplish the legal requirements. Therefore, in order to verify the environmental perception and the knowledge of the consumers about the companies' environmental responsibility, in special the students of the University of Mato Grosso, and the possible influence on its buying decision, a research was accomplished under the form of questionnaires. This study obtained 135 answers which are observed that the students are concerned about environmental issues and in favour of manufacturing companies of products that don't attack the environment in its manufacture. However, in agreement with the answers obtained it is observed that is not still significant the knowledge about the systems of environmental administration adapted, especially to ISO 14001.

Keywords: ISO 14001, environmental perception, influence consumer market

\section{Introdução}

O Sistema de Gestão Ambiental - SGA é a forma pela qual as organizações se mobilizam, interna e externamente, para a conquista do desempenho ambiental desejado.

Desde 1996, as organizações ou as empresas de todos os tipos, portes e nacionalidades têm disponível uma ferramenta de gestão ambiental, a ISO
14001, válida e reconhecida em mais de 100 países do mundo, para auxiliá-las a reduzir os impactos ambientais que causam, além de proporcionar conformidade com a legislação ambiental (FIESP, 2007).

O papel estratégico da gestão ambiental para as organizações tem se evidenciado a partir de uma série de constatações relacionadas ao ambiente onde atuam. As empresas tornaram-se vulneráveis a ações legais e até mesmo recusa por parte dos 
consumidores, que cada vez mais consideram essencial a qualidade ambiental do produto.

Quando analisados os fatores que influenciam a decisão de compra do consumidor, fica perceptível, mediante estudo de diversos autores, a confirmação de que a questão ambiental e a preocupação com a preservação do meio ambiente por parte de empresas e alta camada da sociedade veio para se firmar como até mesmo estratégia de sobrevivência e competitividade (KOTLER, 2006).

Percebe-se então o início do uso do marketing voltado para responsabilidades sociais e ambientais, como forma de atender aos desejos de uma camada da sociedade que já possui suas necessidades básicas e/ ou iniciais supridas e sente-se precisada de fazer algo pelo bem comum.

Nesta perspectiva, a cultura ambiental empresarial surge, não como uma novidade, mas sim, como uma necessidade. O Meio Ambiente torna-se então, um importante fator para o processo decisório das empresas que proporcionará a garantia de competitividade e sobrevivência no mundo globalizado.

O objetivo da pesquisa foi verificar a percepção do estudante universitário, no âmbito da educação ambiental, a respeito da preocupação ambiental por parte das empresas, identificar a existência de preferência por um produto ambientalmente correto bem como valorar a quantia que estudantes de graduação da Universidade Federal de Mato Grosso estão dispostos a pagar por um produto ambientalmente correto.

\section{Revisão Bibliográfica}

Percepção ambiental pode ser definida como sendo uma tomada de consciência do ambiente pelo homem, ou seja, o ato de perceber o ambiente que se está inserido, aprendendo a proteger e a cuidar do mesmo (FAGGIONATO apud FERNANDES et al., 2003).
A percepção ambiental, sendo usada com um instrumento da educação ambiental, poderá ajudar na defesa do meio natural, pois ela aproxima o Homem da sua verdadeira "casa", a natureza, despertando-o para o cuidado e o respeito para com a Terra. Com isso, pode-se ter qualidade de vida para todos e para as novas gerações (PALMA, 2005).

Acredita-se, portanto, ser necessário que a educação ambiental atue para que desse modo as pessoas tenham mais facilidade em perceber o meio em que estão inseridas e da necessidade de preservação. Esta nova visão só poderá se realizar através do conhecimento, entendimento, integração e respeito pelo meio ambiente, capacitando cidadãos que com suas escolhas podem influenciar no comportamento de toda a sociedade, em especial das indústrias.

A concorrência traz a necessidade de criação de um diferencial competitivo que conquiste a preferência dos consumidores. Após o fim da competitividade por preço, a customização ou produto personalizado passou a ser o grande diferencial. Mas hoje, nenhum desses fatores é inédito nos produtos. A imagem que a empresa possui passa a ser fator decisivo de compra para uma fatia cada vez maior da sociedade. Aumenta o número de clientes e consumidores querendo ter a certeza de que a qualidade de suas vidas não está sendo comprometida pelos crescentes interesses empresariais de lucros (DIAMOND, 2007).

Além da reputação, algumas empresas estão usando estratégias ambientais para obter vantagem competitiva seja pela melhoria de custos através do contínuo melhoramento de processos e redução de resíduos (estratégia baseada em custos), seja por alcançar vários segmentos de mercado que são ambientalmente mais sensíveis (estratégia baseada na diferenciação). Diferenciação de produtos e melhoria na imagem da empresa levam a ganhos de mercado, enquanto que melhoria na eficiência de recursos e redução de risco conduzem a reduções de custo (que podem ou não levar a ganhos de mercado) (MILES; COVIN, 2000). 
As primeiras indústrias surgiram em uma época em que os problemas ambientais eram de pequena expressão, em virtude das reduzidas escalas de produção e das populações comparativamente menores e pouco concentradas. As exigências ambientais eram poucas e a fumaça das chaminés era um símbolo de progresso, apregoada orgulhosamente na propaganda de diversas indústrias (DONAIRE, 1999).

Atualmente observa-se poluição de todos os tipos, relacionados principalmente a insensibilidade industrial e a inoperância do poder público para com o meio ambiente que, associadas ao desprezo com a questão ambiental, fazem com que problemas ambientais como a poluição dos recursos hídricos e do ar, desmatamentos, queimadas, contaminação do solo entre outros, sejam tratados em segundo plano. E, assim, a natureza vai se tornando indefesa vítima do progresso econômico e industrial da humanidade (ROLIM, 2003).

Segundo Viterbo (1998), gestão ambiental, nada mais é do que a forma como uma organização administra as relações entre suas atividades e o meio ambiente que as abriga, observadas as expectativas das partes interessadas. Ou seja, é parte da gestão pela qualidade total.

As primeiras iniciativas de modelos de sistemas de gestão ambiental ou SGA surgiram a partir da década de 80 . O mais famoso destes sistemas é o ISO 14001, porém, antes deste, surgiram outros que deram também sua parcela de contribuição para o desenvolvimento e utilização - por parte, sobretudo, das organizações produtivas - destes sistemas que visam identificar, minimizar e controlar aspectos e impactos ambientais (CAMPOS et al, 2006).

A implementação de um Sistema de Gestão Ambiental - SGA - constitui estratégia importante para a organização identificar oportunidades de melhorias que reduzam os impactos das atividades sobre $o$ meio ambiente. Conforme Tinoco e Kraemer (2006), os atuais SGA originaram-se do desenvolvimento de sistemas de qualidade, fornecendo um detalhe adicional no programa ambiental.

Um sistema de gestão ambiental pode ser descrito como uma metodologia pela qual as organizações atuam de maneira estruturada sobre suas operações para assegurar a proteção do ambiente, conforme Figura 1. Elas definem os impactos de suas atividades e, então, propõem ações para reduzi-los. Um SGA tem, portanto, o objetivo de controlar e reduzir continuamente estes impactos (ROWLAND-JONES; CRESSER, 2005).

Figura 1 - Com o SGA, propõe-se a equacionar a complexa relação das organizações com o meio ambiente e com a regulamentação, legal ou técnica, aplicável.

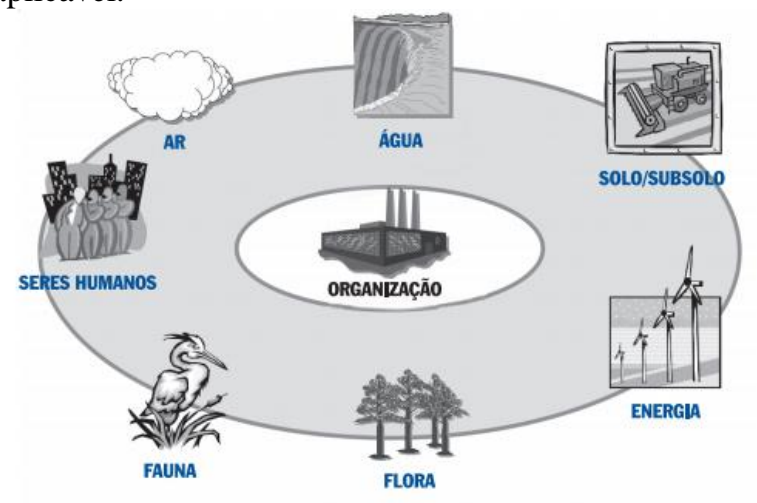

Fonte: Sindicel (2006) apud FIESP (2007)

O SGA não é obrigatório, pois não há legislação que obrigue as empresas a desenvolvê-lo e implementá-lo. Segundo Dias (2007), deve ser levado em consideração que a cada dia torna-se maior a exigência da adoção desses sistemas de gestão sustentáveis, por parte principalmente dos clientes, do mercado internacional e das instituições públicas, implicando mudanças culturais e estruturais dentro das organizações, passando por todos os setores iniciais até a alta administração.

O modelo de Sistema de Gestão Ambiental para a NBR 14001, com inspiração nos sistemas de gestão da qualidade, foi concebido no formato fundamentado no chamado Ciclo PDCA Planejar, Executar, Verificar e Agir (Plan, Do, Check, Act, em inglês). A NBR ISO 14001 apresenta, de forma genérica, instruções necessárias para o funcionamento 
de um SGA. Não existem orientações específicas para a forma como rotinas devem ser formuladas, implantadas ou gerenciadas e, portanto, é uma tarefa importante no processo de certificação a sua interpretação e adaptação à realidade da empresa (OELREICH, 2004).

Embora a norma ISO 14001 seja detalhada na exigência dos procedimentos que devem ser adotados na implantação do SGA, segundo Dias (2007), não estabelece metas, podendo ser adotada por organizações de qualquer tipo e tamanho. Dentre os benefícios que podem ser obtidos ao adotar um SGA, as normas ajudam a empresa a transmitir confiança às partes interessadas de que existe um comprometimento da administração para atender às políticas, metas e objetivos; há maior ênfase à prevenção do que às ações corretivas; fornecesse evidências da atuação cuidadosa e do atendimento aos requisitos legais; e possibilita-se a inclusão do processo de melhoria contínua.

Depois que o SGA está implantado e operando, ele pode ser certificado, isto é, pode-se obter o reconhecimento oficial de que ele atende os requisitos da norma NBR ISO 14001. Segundo Tagliaferro (2000) a comprovação desses requisitos é feita por entidades independentes. Sendo assim, será necessária a contratação de uma empresa certificadora que fará uma auditoria do Sistema. Caso tudo esteja em plena conformidade essa certificadora recomendará a certificação ao INMETRO que é o órgão acreditador brasileiro, isto é, o órgão que valida oficialmente, as certificações no Brasil.

Segundo Pombo e Magrini (2008) os custos para adoção da norma ISO 14001 são similares àqueles para adoção da norma ISO 9000 de gestão da qualidade, como reportado por Miles et al (1997). Os altos custos relacionados à implementação da norma ISO 14001 podem, de fato, tornar-se uma barreira para a entrada de muitas pequenas empresas. Entretanto, esses altos custos podem deixar de ser uma barreira na medida em que a empresa comece com um sistema de gestão ambiental básico, gradualmente transformando-o em um sistema mais sofisticado.

Alberton (2003) descreveu que talvez uma das maiores vantagens da adoção dos modelos de gestão ambiental e da certificação seja a demonstração pública da conformidade a padrões reconhecidos nacional e internacionalmente. Já no campo da estratégia, a manutenção da competitividade das organizações em mercados cada vez mais disputados pode proporcionar um diferencial e vantagem competitiva às empresas, principalmente para aquelas que exportam para o mercado europeu tendo em vista que algumas das exportações realizadas pelos segmentos considerados potencialmente poluentes - aos países onde há uma maior preocupação ecológica - estão condicionadas aos certificados de qualidade ambiental.

Além dos benefícios proporcionados às muitas partes interessadas, observa-se atualmente um crescimento dos requisitos legais, onde seu cumprimento é obrigatório, independente de as empresas terem ou não um SGA. Por isso, a certificação resulta em ganhos financeiros reais (redução de custos), já que evita multas ambientais, além de maior transparência e confiança junto aos órgãos fiscalizadores (SEBRAE, 2004). Vale acrescentar que outras reduções de custo podem ser obtidas, após a certificação, com a otimização dos processos, redução do uso de recursos materiais, redução dos riscos de acidentes e seus encargos. Nesse sentido, segundo Viterbo (1998), a certificação ISO 14001 não é necessariamente cara, depende fundamentalmente da natureza da organização e dos aspectos ambientais e impactos identificados. Entretanto, ela pode atingir valores proibitivos em curto prazo se o "passivo ambiental" for grande (por exemplo, contaminação do solo ou do lençol freático) ou não houver o atendimento à legislação ambiental, nem viabilidade de vir a atendê-la num prazo considerado razoável pelo organismo de controle ambiental.

De acordo com o histórico que temos acompanhado, em 1999, o Brasil teve o 
mérito de ser o primeiro país da América Latina a alcançar a marca das 100 certificações em conformidade com a Norma ISO $14001 \mathrm{e}$, desde esta marca, vem vivenciando um histórico de sucesso crescente nesse cenário sendo que em 2011, com o volume de 5.000 certificações, consolida-se como o país com o maior número de certificados emitidos na América Latina. (Revista Meio Ambiente Industrial, 2011). A evolução das certificações no Brasil pode ser visualizada na Figura 2.

Figura 2 - Evolução das Certificações ISO 14001 no Brasil. Fonte: Revista Meio Ambiente Industrial (2011).

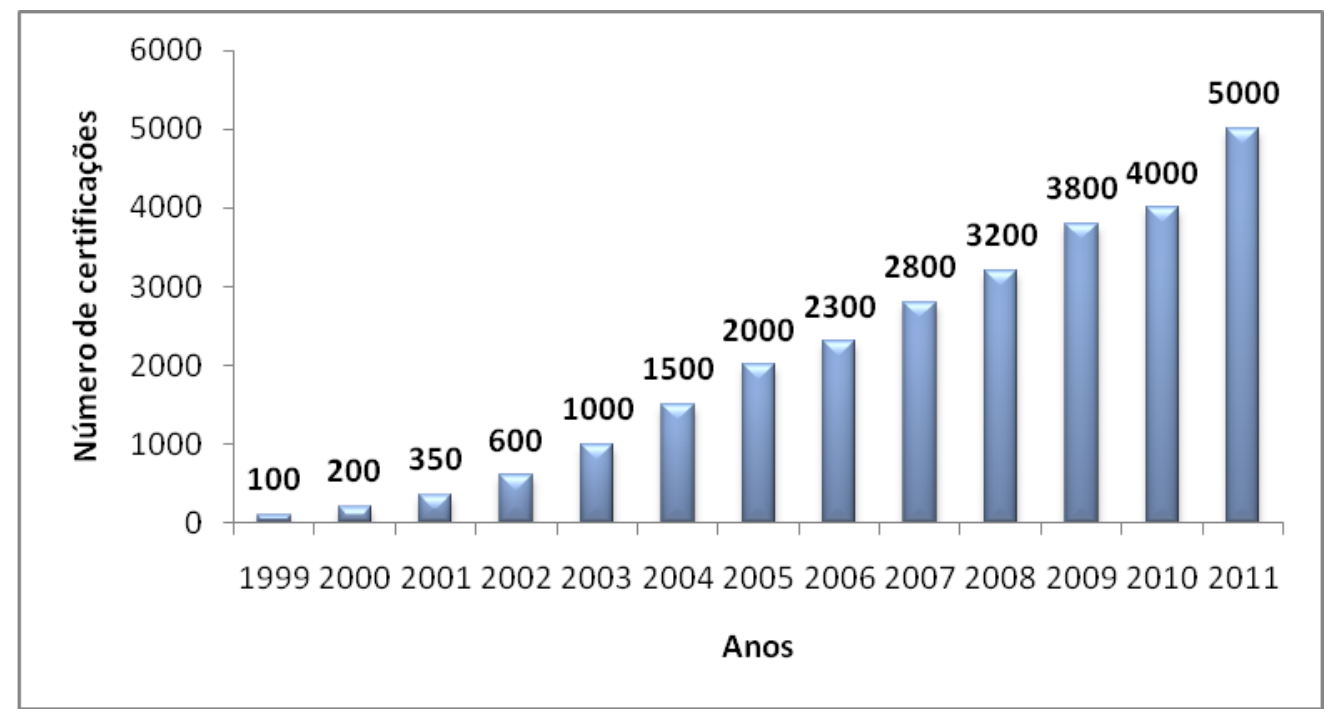

Além disso, segundo dados da International Organization for Standartization (2010), que levou em consideração os resultados acumulados até 2010, o Brasil tem se destacado no cenário mundial com o avanço no número de certificações, conforme Tabela 1. Nota-se que a China foi a campeã com um crescimento de 14.468 certificados, o Brasil apresenta um crescimento nessa área, foi $07^{\circ}$ maior crescimento do mundo com 1.488 novos certificados.

Tabela 1 - Brasil no cenário mundial quanto ao crescimento do número de novos certificados em 2010.

\begin{tabular}{ccc}
\hline Posição & País & $\begin{array}{c}\text { Número de } \\
\text { Certificações }\end{array}$ \\
& China & 14.468 \\
$1^{\circ}$ & Reino Unido & 3.434 \\
$2^{\circ}$ & Itália & 2.522 \\
$3^{\circ}$ & República Tcheca & 1.945 \\
$4^{\text {o }}$ & Coréia do Sul & 1.838 \\
$5^{\circ}$ & Espanha & 1.820 \\
$6^{\circ}$ & Brasil & 1.488 \\
$7^{\circ}$ & Romênia & 555 \\
$8^{\circ}$ & Coréia do Norte & 468 \\
$9^{\circ}$ & Colômbia & 466 \\
\hline $10^{\circ}$ & &
\end{tabular}

Na Tabela 2 é apresentado o número total de empresas certificadas pela ISO 14001 por regiões até 2005 (REVISTA MEIO AMBIENTE INDUSTRIAL, 2005). Percebe-se claramente uma predominância significativa de empresas certificadas na região sudeste, em virtude principalmente do Estado de São Paulo. Este fato pode ser justificado por ser este o estado brasileiro mais industrializado. Os estados que possuem menos certificações estão localizados na região Centro Oeste.

Tabela 2 - Distribuição por regiões das empresas que foram certificadas em conformidade com a norma 14001 até 2005 .

\begin{tabular}{cc}
\hline Estados da Federação & Total \\
Nordeste & $10,7 \%$ \\
Norte & $4,5 \%$ \\
Centro Oeste & $1,2 \%$ \\
Sudeste & $66,5 \%$ \\
Sul & $17,1 \%$ \\
Total Brasil & $100 \%$ \\
\hline
\end{tabular}

Fonte: Revista Meio Ambiente Industrial (2005). 
Citação: Marques M., Marchetto M, Temponi J.R. e Ferreira Leite S.C. A Percepção Ambiental pelos Alunos da UFMT- Campus Cuiabá como Instrumento de Planejamento de Sistemas de Gestão Ambiental nas Empresas. E\&S - Engineering and Science, (2014), 2:1.

\section{Materiais e Métodos}

A UFMT já formou quase $50 \mathrm{mil}$ profissionais e oferece 101 cursos de graduação regulares em todos os campi.

A Universidade Federal de Mato Grosso é responsável pela maior produção científica no Estado, integrando redes nacionais $\mathrm{e}$ internacionais de investigação. Nos últimos anos, promoveu aumento de quase $400 \%$ no número de grupos de pesquisa.

A partir dessas informações inferimos que a Universidade Federal de Mato Grosso, vem apresentando um alto crescimento na formação de jovens para o mercado de trabalho nas últimas décadas decorrente de seu desenvolvimento. Sendo assim, o trabalho visa obter maior conhecimento acerca da preocupação por parte dessa população quanto às questões ambientais.

A fundamentação teórica realizada demonstrou que a preocupação ambiental por parte das empresas é um fator relevante para o mercado de consumidores. Essa preocupação de certa forma influenciou o desenvolvimento apresentado no Brasil e no estado de Mato Grosso no que se refere à preocupação ambiental e ao movimento de certificações na norma ISO 14001.

Foram realizadas entrevistas com a comunidade universitária, buscando perceber a real situação do conhecimento dos consumidores relativo aos assuntos do ambiente, sobre as indústrias e suas práticas ambientais, e da importância de serem certificadas pela ISO 14001.

Para a coleta de dados desta pesquisa utilizou-se da adequação e aplicação de questionários, objetivando uma percepção de forma clara sobre opiniões e comportamentos prováveis de consumidores onde se buscou investigar a preocupação do consumidor com as questões ambientais e como isso pode refletir no comportamento das empresas quanto à preocupação por uma conformidade ambiental, em especial à certificação ISO 14001.

O questionário foi uma adaptação conforme os trabalhos de Fernandes (2003) e Buosi (2008), além da colaboração de especialistas tanto da área de meio ambiente quanto da área de estatística. Que contemplou as dimensões: Perfil Socioeconômico, Percepção Ambiental e Gestão Ambiental.

Desse modo, o questionário após ser elaborado foi encaminhado à especialistas da área para uma avaliação crítica do instrumento e com o objetivo de torná-lo apto a ser aplicado em campo. Após passarem por essa etapa de validação, foi realizado um pré-teste com 20 pessoas pertencentes à população amostra do trabalho, para identificação e correção de possíveis problemas durante a sua aplicação.

O método escolhido para a realização da definição da população a ser entrevistada foi o de amostragem não probabilística por conveniência, onde o pesquisador seleciona membros da população mais acessíveis. A amostra foi composta por 135 alunos da graduação das áreas de Exatas, Biológicas e Humanas da UFMT/Cuiabá.

O questionário foi elaborado utilizando a plataforma Google Docs, uma ferramenta gratuita onde é possível a elaboração de textos, planilhas, formulários de forma online. Quando finalizado, o questionário é publicado em um endereço na internet próprio do sistema estando apto para receber respostas. Após sua publicação ele pode ser encaminhado via e-mail.

Para a pesquisa foram selecionados os estudantes de graduação da Universidade Federal de Mato Grosso, a fim de verificar, o conhecimento assim como a preocupação/percepção acerca das questões ambientais principalmente no que se refere às indústrias. Eles receberam via e-mail o questionário durante o mês de setembro de 2012, podendo responder até o mês de outubro de 2012.

Os dados coletados foram tabulados e apresentados de forma comparativa e através de análise descritiva, com frequências $\mathrm{e}$ porcentagens, por meio de tabelas, quadros e gráficos, auxiliando na organização das informações para a análise.

\section{Resultados e Discussões}

O questionário, em sua primeira parte, buscou identificar o perfil sociodemográfico do 
estudante universitário quanto a: faixa etária, sexo, se possui outro tipo de ocupação além de estudante, estado civil e renda familiar, além destes também foram identificados também a situação do universitário em relação à área de estudo e período em que se encontra, de forma que esses dados pudessem ser levados em consideração na análise dos resultados da pesquisa.

Dentre os entrevistados $48 \%$ são do sexo masculino e $52 \%$ feminino, com idade média de 22 anos, e $95 \%$ se autodeclararam solteiros. Observou-se que parcela expressiva dos estudantes são de classe média, cerca de $46 \%$.

A participação por curso (Tabela 3), a amostragem captou respostas de 24 cursos dentro da Universidade Federal de Mato Grosso. A área de exatas correspondeu a maior participação e o curso de Engenharia Sanitária e Ambiental foi o curso com maior participação correspondendo a $26 \%$ do total de entrevistados, esse fato pode ser explicado devido ao curso ser o mais ligado dentre todos à assuntos de meio ambiente.

Tabela 3 - Distribuição dos entrevistados por curso

\begin{tabular}{lc}
\hline Área & Participação $(\mathrm{n}=135)$ \\
Humanas & $26 \%$ \\
Exatas & $58 \%$ \\
Biológicas & $16 \%$ \\
Total & $100 \%$ \\
\hline
\end{tabular}

Os dados apresentados na primeira parte da pesquisa permitem, na realização de uma análise cruzada das informações, a busca pelo perfil do consumidor que atribui relevância para as questões e responsabilidades ambientais e diferenciá-los daqueles que não levam em consideração esses fatores em sua decisão de compra, ou atribuem pouca relevância.

$\mathrm{Na}$ segunda parte da pesquisa incluíam-se questões gerais relativas ao meio ambiente onde se buscava perceber a atitude dos entrevistados em relação às questões ambientais, 95\% dos respondentes disseram ter interesse em assuntos relacionados ao meio ambiente, quando ao questionamento sobre se possuíam algum tipo de incômodo com aspectos negativos relacionados ao meio ambiente tais como ruído, desmatamento, entre outros, $94 \%$ dos respondentes afirmaram se sentir incomodados com algum tipo de aspecto negativo. $\mathrm{O}$ resultado encontrado vai ao encontro do obtido por Fernandes (2003) onde a resposta para essas duas questões totalizaram $90,1 \%$ e $87,8 \%$, respectivamente.

Com relação a responsabilidade em proteger o meio ambiente, $90 \%$ confirmaram que a deve ser compartilhada por toda a sociedade. Quanto ao responsável pelos danos ocasionados ao meio ambiente os respondentes consideraram a sociedade em geral seguida das indústrias (Figura 3).

Figura 3: - Responsáveis pelos danos ao meio ambiente na opinião dos entrevistados.

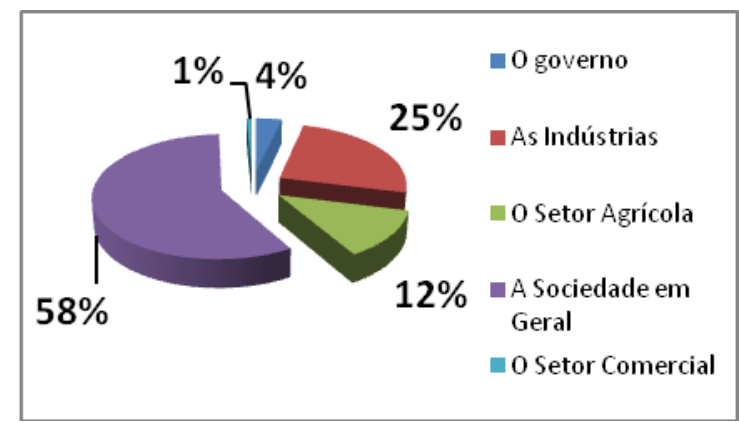

Sobre a importância dada pelos estudantes universitários na compra de um produto quanto aos seguintes aspectos: preço, embalagem, marca e o produto ser ambientamente correto. O respondente poderia atribuir $\mathrm{o}$ grau de importância para cada aspecto, independente de já haver dado o mesmo grau de importância para outro aspecto. Os resultados apontaram com ampla vantagem, 66\%, o quesito preço foi considerado muito importante (peso 5) pela maioria dos entrevistados na compra de um produto. Em segundo lugar, com 18\%, como muito importante aparece o aspecto de a empresa ser ambientalmente correta. Para cerca de $40 \%$ dos participantes da entrevista, o ambientalmente correto é um quesito indiferente (peso 3) porém o percentual de indiferente para demais quesitos exclusive preço é também de cerca de $40 \%$. Entre os participantes que associaram ser muito importante o produto ser ambientalmente correto cerca de $70 \%$ são do sexo feminino, $70 \%$ também são pertencentes ao últimos anos de curso.

A terceira parte foi composta por questões mais específicas de gestão ambiental, onde se 
buscou conhecer o estudante universitário que possui informações acerca do entendimento do comprometimento necessário para as empresas.

Sobre o conhecimento por parte do estudante universitário a respeito do sistema de gestão ambiental mais utilizado pelas empresas: a ISO 14001. A maioria dos respondentes, 61\%, afirmaram não conhecer a ISO 14001. Esta questão foi de caráter eliminatório onde a partir desta apenas os estudantes que possuíam conhecimento sobre a ISO 14001 continuaram a responder o questionário.

Figura 4 - Importância atribuída em relação ao preço, embalagem, marca e produto ambientalmente correto.

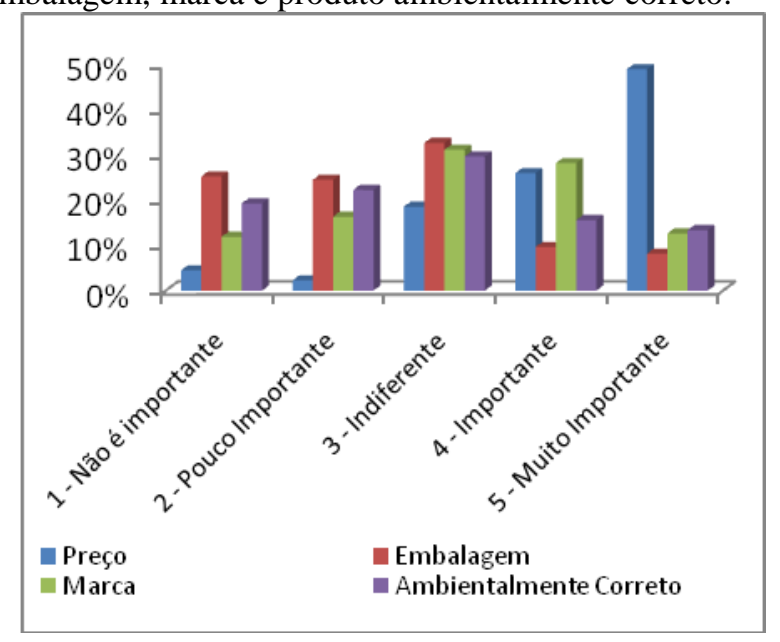

sexo feminino 54\%, não havendo, portanto, diferença considerável entre os gêneros. Com relação ao número total de respondentes por curso que conheciam a ISO 14001, a maioria $75 \%$ que disseram conhecer a norma, pertence ao curso de Administração, e 57\% pertencem ao curso de Engenharia Sanitária e Ambiental, Além disso, entre todos os cursos os estudantes que responderam sim a pergunta, em sua grande maioria, são pertencentes aos últimos anos de seu respectivo curso.

Quanto a importância atribuida as empresas que possuem a certificação ISO 14001, observamos $54 \%$ dos estudantes que conhecem a ISO 14001 acham muito importante (peso 5) e $38 \%$ acham importante (peso 4) a empresa ser certificada. E sobre a questão se trocaria um produto que consome ultimamente por outro se este se tornasse certificado, $27 \%$ dos entrevistados responderam muito provavelmente (peso 5) trocariam o produto por um menos agressivo ao meio ambiente seguidos de um pouco provável com $29 \%$ (peso 4), somando juntos $56 \%$ que estariam dispostos a trocar de um produto por outro que se tornou certificado, demonstrando a importância que atribuem às empresas serem certificadas, Figura 5.

Entre os estudantes que disseram ter conhecimento em relação à norma a maioria é do

Figura 5: Disposição dos entrevistados em trocar um produto que consome atualmente por um certificado

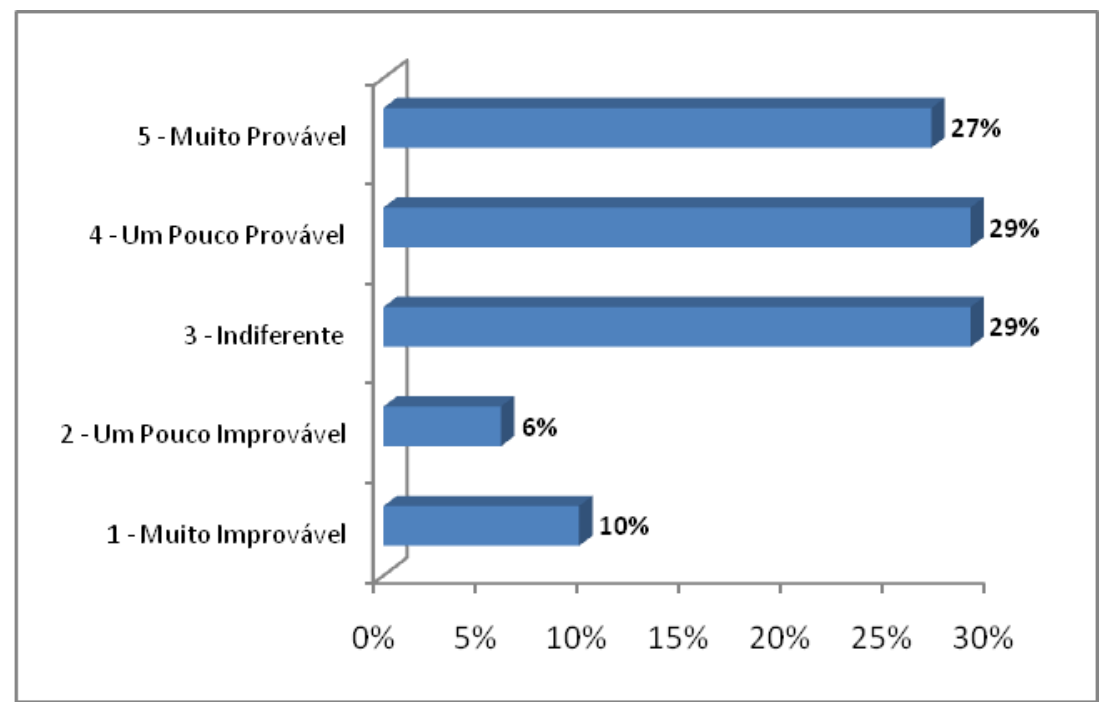


Os métodos de valoração ambiental têm grande importância para a sustentabilidade, pois além de dimensionarem os impactos ambientais que são internalizados à economia, possibilitam a evidência dos custos e benefícios inerentes à expansão da atividade humana (MATTOS; MATTOS, 2004).

Desse modo, a última pergunta questionava os estudantes universitários quanto ao reconhecimento que seria dado as empresas através da valorização do produto, essa questão era aberta e os estudantes poderiam colocar o valor que desejassem. Considerando isoladamente, a maioria dos consumidores, cerca de $23 \%$, considerou que a empresa tem obrigação de seguir as normas ambientais não estando dispostos a pagar nada a mais por ela ser certificada, apesar de todo o investimento necessário demonstrado na revisão bibliográfica. De maneira geral, $77 \%$ da população entrevistada estariam dispostas a pagar um valor a mais pelo mesmo produto considerando o valor base de $\mathrm{R} \$ 1,00$. Falando em termos percentuais, a quantidade paga a mais pelo produto estaria em uma variável de 5 à $25 \%$ sobre o valor, para $23 \%$ da população entrevistada e 50 à $100 \%$ para $44 \%$ da população.

\section{Conclusões}

A percepção ambiental entre a comunidade universitária é relevante, principalmente no instante em que a mesma se considera como a principal causadora pelos danos ao meio ambiente assim como a principal responsável em proteger o mesmo, comprometendo-se com as causas ambientais. A conscientização ambiental vem aumentando significativamente, entretanto, ainda observa-se que a escolha por um produto é norteada pelo preço.

O conhecimento a respeito da ISO 14001 demonstrado foi relativamente pequeno, fato este que demonstra o quanto os alunos de graduação da UFMT necessitam de mais informações com relação as questões ambientais.
De maneira geral a pesquisa demonstrou a preferência dos estudantes universitários por um produto ambientalmente correto à medida que $\mathrm{o}$ quesito de a empresa ser ambientalmente responsável aparece em segundo lugar como mais importante na escolha de um produto.

Entre os conhecedores da norma essa preferência também acontece, onde a maioria dos respondentes acredita ser importante a empresa ser certificada assim como trocaria um produto que consome atualmente por outro que seria menos agressivo ao meio ambiente.

Quanto à valoração atribuída aos produtos que possuem certificação, grande parcela dos estudantes da Universidade Federal de Mato Grosso da amostra estariam dispostos a pagar mais de $50 \%$ em relação ao preço original por um produto certificado.

Por fim, a percepção ambiental é um meio de compreender como os sujeitos da sociedade adquirem seus conceitos e valores, bem como, como compreendem suas ações e se sensibilizam com questões ambientais. Desse modo, a pesquisa mostrou que a percepção ambiental por parte dos estudantes de graduação faz com que esta se sinta responsabilizada em relação aos problemas ambientais a ponto de preferir comprar produtos de empresas que colaborem com a preservação do meio ambiente.

\section{Referências Bibliográficas}

ALBERTON, A. Meio Ambiente e Desempenho Econômico - Financeiro: Impacto da ISO 14001 nas Empresas Brasileiras. 2003. 285 f. Tese - Engenharia de Produção e Sistemas, Universidade Federal de Santa Catarina, Florianópolis, 2003.

\section{BUOSI, M. C. A. A norma ISO 14001 como fator de} competitividade. Uma análise no mercado de águas minerais. 2008. 73-74 f. Trabalho de conclusão de curso Faculdade de Economia, Administração, Atuária, Contabilidade e Secretariado Executivo, Universidade Federal do Ceará, Fortaleza, 2008.

CAMPOS L. M. S. et al. Os sistemas de gestão ambiental: empresas brasileiras certificadas pela norma ISO 14001. In: ENEGEP - ENCONTROS NACIONAIS DE ENGENHARIA DE PRODUÇÃO, 26., 2006, Fortaleza. Disponível em: <http://www.abepro.org.br/biblioteca/ENEGEP2006_TR5 20346_7815.pdf>. Acesso em: 21 mar. 2012. 
Citação: Marques M., Marchetto M, Temponi J.R. e Ferreira Leite S.C. A Percepção Ambiental pelos Alunos da UFMT- Campus Cuiabá como Instrumento de Planejamento de Sistemas de Gestão Ambiental nas Empresas. E\&S - Engineering and Science, (2014), 2:1.

DIAMOND, J. Como as sociedades escolhem o fracasso ou o sucesso. Rio de Janeiro: Editora Record: 2006.

DIAS, R. Gestão ambiental: responsabilidade ambiental e sustentabilidade. 1. ed. 2. reimp. São Paulo: Atlas, 2007.

DONAIRE, D. Gestão ambiental na empresa. $2^{\mathrm{a}}$ ed. São Paulo: Atlas, 1999.

FERNANDES, R. S. et al. Uso da percepção ambiental como instrumento de gestão em aplicações ligadas às áreas educacional, social e ambiental. Vitória, 2003. Disponível em <http//:www.redeceas.esalq.usp.br / Percepção_Ambiental.pdf $>$ Acesso em 19 de setembro de 2012.

FIESP. Melhore a competitividade com o Sistema de Gestão Ambiental - SGA. São

Paulo: FIESP, 2007.

\section{INTERNATIONAL ORGANIZATION FOR} STANDARTIZATION. The ISO Survey. 2010. Disponível no site do International Organization for Stardartization na internet. URL: < http://www.iso.org/iso/iso-survey2010.pdf >. Acesso em: 01 jun. 2012

KOTLER, P. Administração de marketing. $12^{\mathrm{a}}$ edição. São Paulo: Pearson Prentice Hall, 2006.

MATTOS, K. M. C.; MATTOS, A. Valoração econômica do meio ambiente: uma abordagem teórica e prática. São Carlos: Rima Fapesp, 2004.

MILES, M. P. et al. Marketing and environmental registration/certification - what industrial marketers should understand about ISO 14001. Industrial Marketing Management, Oxford, v. 26, n. 4, p. 363-370, 1997.

MILES, M. P.; COVIN, J. G. Environmental marketing: a source of reputational, competitive and financial advantage. Journal of Business Ethics. Dourdrecht, v.23,p. 299-311, 2000 .

OELREICH, K. V. Environmental certification at Mälardalen University. International Journal of Sustainability in Higher Education, v. 5, n. 2, p. 133-146, 2004.
PAlMA, I. R. Análise da Percepção Ambiental Como Instrumento ao Planejamento da Educação Ambiental. 2005. 83 f. Dissertação - Engenharia de Minas, Metalúrgica e de Materiais, Universidade Federal do Rio Grande do Sul, Porto Alegre, 2005.

POMBO, F. R.; MAGRINI, A. Panorama de aplicação da norma ISO 14001 no Brasil. Revista Produção, v. 15, n. 1, p. 1-10, 2008.

REVISTA MEIO AMBIENTE INDUSTRIAL. A evolução das certificações ISO 14.001 no

Brasil. Edição Especial ISO 14.000, mai. 2005.

REVISTA MEIO AMBIENTE INDUSTRIAL. A evolução das certificações ISO 14.001 no Brasil. Edição Especial ISO 14.001, Mai - Jun. 2011.

ROLIM, A. Qualidade de Sistemas de Gestão Ambiental (artigo), 2003. Disponível em: < www.gestaoambiental.com.br/articles.php?id=3> Acesso em 21 jul. 2012.

ROWLAND-JONES, R.; CRESSER, M. An evaluation of current environmental management systems as indicators of environmental performance. Management of Environmental Quality: An International Journal, v. 16, n. 3, p. 211-219, 2005.

SERVIÇO BRASILEIRO DE APOIO ÀS MICRO E PEQUENAS EMPRESAS - SEBRAE. Curso Básico de Gestão Ambiental. Brasília: Sebrae, 2004. 111p.

TINOCO, J. E. P.; KRAEMER, Maria Elisabeth Pereira. Contabilidade e gestão ambiental. 1. ed. 2. reimp. São Paulo: Atlas, 2006.

TAGLIAFERRO, E. R. ISO 14001: Certificado ou Atestado de Excelência Ambiental? Monografia, UNORP, 2000.

VITERBO, J. E. Sistema Integrado de Gestão Ambiental: Como implementar um sistema de gestão que atenda à norma ISO 14001, a partir de um sistema baseado na norma ISO 9000. São Paulo: Aquariana, 1998.

Marques, Mayara Cristina Santos. A Percepção Ambiental como Instrumento de Planejamento de Sistemas de Gestão Ambiental nas Empresas. Trabalho de Conclusão de Curso 2012. 